\title{
Correction: $R$-ketamine: a rapid-onset and sustained antidepressant without psychotomimetic side effects
}

C. Yang, Y. Shirayama, J-c Zhang, Q. Ren, W. Yao, M. Ma, C. Dong and K. Hashimoto

Correction to: Translational Psychiatry

https://doi.org/10.1038/tp.2015.136

published online 01 September 2015

In the original Article, Figs. 2 and 4 were incorrect due to a duplication error. We cannot update the original Article as we no longer use the software on which it was processed, so we are providing the correct figures here in this correction notice.

Published online: 21 August 2020 


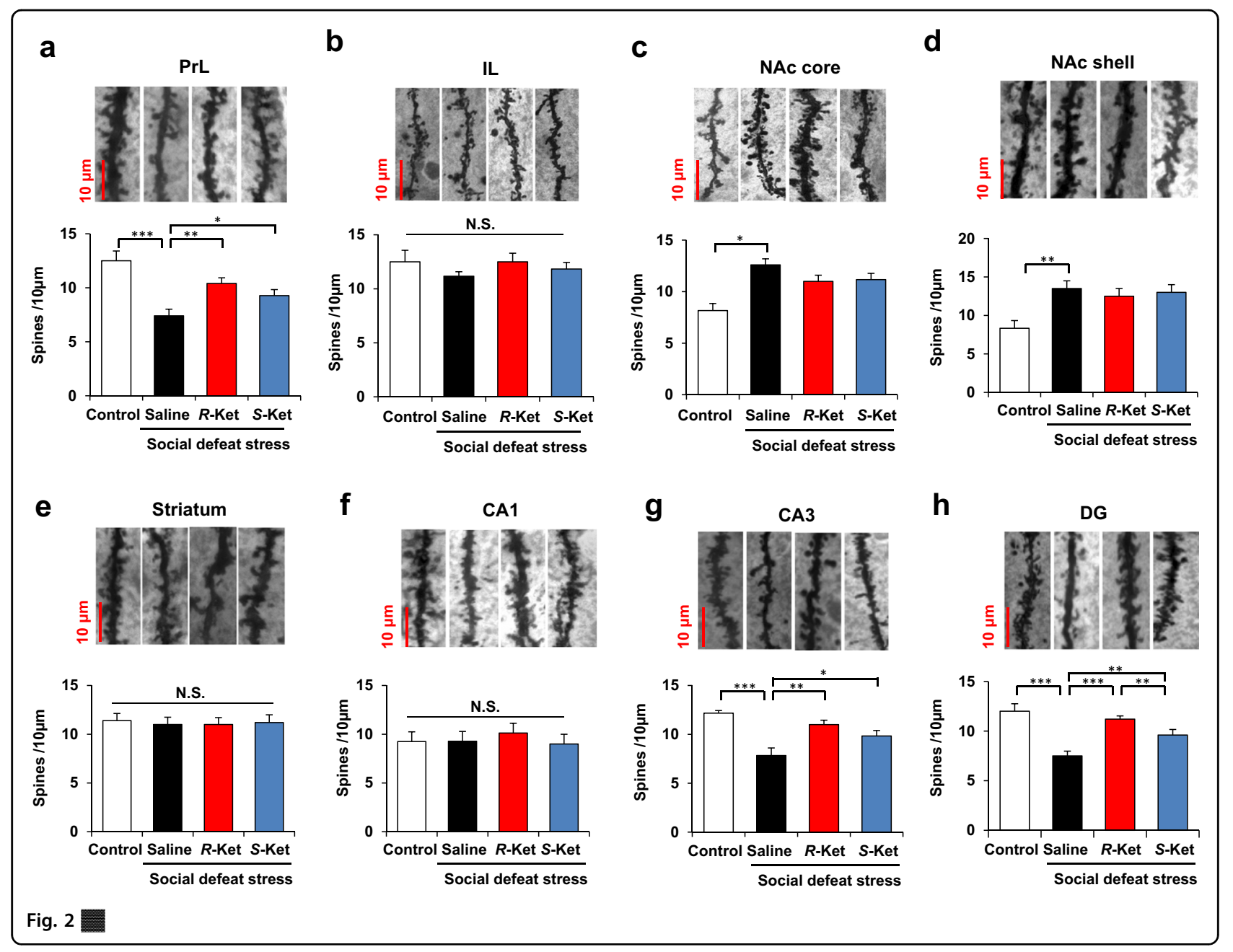




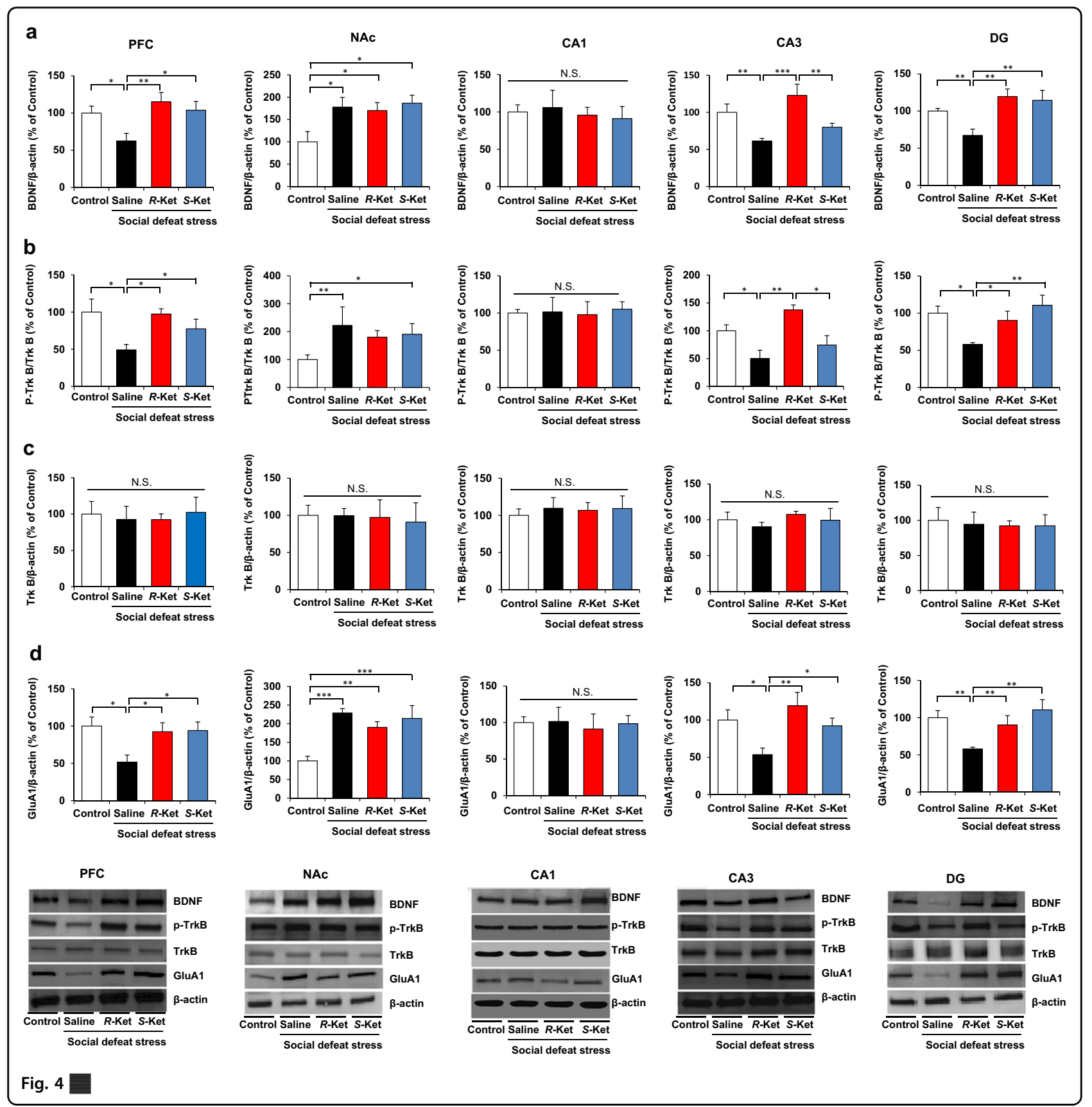

